\title{
Vida en el Campo Versus Vida en la Ciudad: narrativas contemporáneas de resistencia campesina en la canción popular ${ }^{1}$
}

\author{
Marlon Javier Méndez-Sastoque ${ }^{2}$
}

\begin{abstract}
Resumen: Siguiendo postulados del análisis sociocrítico, en un contexto social que incita al abandono del campo, se exploran los sistemas de creencias sobre vida en el campo y vida en la ciudad que alientan la decisión de permanencia, en dos canciones que expresan el sentir reivindicativo de pobladores campesinos acerca de la buena vida en sus espacios rurales de origen. El análisis se centra en identificar: a) tensiones, contradicciones y conflictos asociados a "vida en el campo" y "vida en la ciudad", b) formas ideológicas subyacentes en diálogo, y c) cuestionamientos específicos al discurso dominante. Se concluye que, en el contexto de estudio, las categorías "vida en el campo" y "vida en la ciudad" mantienen su vigencia no como descriptoras de dos maneras diferentes de vida, con características fijas y sustantivas opuestas, sino como formas complementarias de expresar los efectos del avance diferenciado y progresivo de la lógica capitalista urbano industrial de desarrollo sobre la sociedad como un todo, incluyendo la resistencia a dicha propensión.
\end{abstract}

Palabras clave: campo y ciudad, migración campo-ciudad, representaciones de campo y ciudad, rural y urbano, canción popular.

Abstract: Following the postulates of sociocritical analysis, in a social context that subordinates the rural to the urban, representations of life in the countryside and life in the city that support the decision of permanence are explored in two songs that express the arguments in favor of peasants about the good life in their rural areas of origin. Focuses on identifying: a) tensions, contradictions and conflicts associated with "life in the countryside" and "life in the city", b) intrinsic ideologies in dialogue and c) specific questions to the dominant discourse. It is concluded that, in the context of the study, the categories of life in the countryside and life in the city maintain their validity not as descriptors of two different ways of life, with fixed and substantive opposing characteristics, but

1. Data de submissão: 1o de fevereiro de 2017. Data de aceite: 11 de setembro de 2017.

2. Universidad de Caldas, Facultad de Ciencias Agropecuarias, Manizales, Caldas, Colombia. E-mail: marlon.mendez@ucaldas.edu.co 
as complementary ways of expressing the effects of different and progressive advance of the urban industrial capitalist logic of development on society, including resistance to this trend.

Key-words: countryside and city, countryside-city migration, rural and urban representations, rural and urban, popular song.

Clasificación JEL: I31, O18, R23.

DOI: http://dx.doi.org/10.1590/1234-56781806-94790560205

\section{Introducción}

Como extensionista y estudioso de los asuntos rurales, convivir con habitantes del campo, observarlos en su vida cotidiana, escucharlos hablar sobre lo que pasa por sus mentes y leer los textos que producen es un ejercicio cotidiano. En esta práctica, cuando la gente habla de su vida, principalmente en conversaciones informales evocadoras del pasado e ilustrativas del presente, hay un tema que surge con cierta regularidad: las diferencias entre el campo y la ciudad, planteadas y argumentadas a partir de la experiencia vivida, así como basadas en la creación imaginaria de escenarios que encarnan sus suposiciones y añoranzas.

Hablan de ello quienes, en distintas circunstancias, concretaron la experiencia migratoria, vivieron en la ciudad y luego optaron por regresar al campo, mas también quienes nunca han vivido en la ciudad, pero han nutrido su intelecto de lo dicho, callado y vivenciado por otros. En estos actos de habla, las diferencias entre ambos espacios se definen y recrean en términos de lo que significa vivir en uno u otro: "vivir en el campo" o "vivir en la ciudad" como referentes casi siempre antagónicos. Antagonismo surgido en un espacio social más amplio, un país o una región como Colombia o América Latina, donde históricamente lo rural ha sido subordinado a lo urbano y donde la vida en la urbe, sobre todo en la gran ciudad, en lo habitual aún se asume como jerárquicamente superior.

Es bajo el influjo de este esquema de subalternidad, según el cual vivir y trabajar en el campo es considerado de menor valía en relación con hacerlo en la ciudad (MAGNO, DOULA y PINTO, 2012, p. 308), que algunos habitantes rurales identifican, expresan y sustentan otras versiones de los hechos. Si bien "el mensaje que la sociedad colombiana ha dado a los pobladores rurales ha sido que su progreso y el de sus familias depende de abandonar el campo" (PNUD, 2011, p. 27), amparados en sus vivencias, incluidas y recreadas en sus conversaciones, historias y relatos, dichos actores develan y comunican la existencia de una ciudad paralela a la vanagloriada: una ciudad inequitativa y fragmentada, en la que también cohabitan la riqueza y la pobreza, donde el acceso a bienes públicos y empleo no está garantizado, en general agresiva con quien llega de afuera.

Con estos relatos e historias de vida, bien sean contados intergeneracionalmente o entre pares etarios, se espera que quienes estén proyectando su partida tengan más referencias sobre lo que enfrentarían en la ciudad. En este caso, lo narrado por alguien y escuchado por otros sobre la vida en la ciudad tendría una función principal: recordarles y comunicarles a esos otros las cosas que sucedieron en el pasado, lo ya por sus congéneres experimentado, para advertirles en el presente las condiciones de un posible futuro (FRITH, 2001).

Siguiendo esta línea, como práctica social, acrecentar y accionar la memoria colectiva sería el papel atribuido a las narraciones compartidas (VICH y ZAVALA, 2004, p. 18). Con la información apropiada y procesada, quienes piensan migrar 
tendrían más elementos para repensar o transformar su proyecto, reconsiderando, en este caso, las ideas o representaciones dominantes acerca de "la buena vida en la ciudad", generalmente orientadoras de la decisión migratoria. Se trataría de un ejercicio de politización de la memoria, donde la oralidad contribuiría a producir contra-memoria a partir de la incorporación de la versión subordinada (OSLENDER, 2003, p. 222): la vida amena en el campo expresada y caracterizada por los propios campesinos, por un lado, y las dificultadas asociadas a vivir en la urbe por ellos mismos percibida, por el otro.

En el marco de la oralidad y sus múltiples formas de expresión, exponer la otra versión, la que resiste a las percepciones dominantes, puede y suele hacerse recurriendo a una de ellas: la musicalización de la palabra. Como forma de expresión de un grupo, en términos generales, más allá de distraer o amenizar un momento, los textos musicalizados son usados para reconstruir hechos o circunstancias de interés, para describirlos y dotarlos de sentido, al comunicar y exponer las emociones a ellos asociadas y los juegos de poder que allí se configuran (SÁNCHEZ, 2014, p. 196). En esta línea, actores sociales los usan como medio para exponer críticamente la realidad que perciben, compartir percepciones sobre concepciones de mundo (HORMIGOS y MARTÍN, 2004, p. 260) e inducir actitudes frente a los hechos evocados.

En términos similares, como portadora de conciencia colectiva, la canción habla a propios y foráneos acerca de las formas de ser, pensar y actuar de un grupo. Relata historias sobre las condiciones materiales existentes, los controles y preceptos morales operantes, las formas de trabajo y producción predominantes y las jerarquías y relaciones de poder emergentes en la interacción con otros (OSLENDER, 2005, p. 74-75). Además de denunciar hechos dañinos para el grupo (2005, p. 97), la canción recuerda aciertos y errores del pasado de los que el colectivo alguna lección ha aprendido.

En el caso de estudio, la faceta de la realidad percibida, aquella que se describe y dota de sentido en las canciones, que se enfatiza e incorpora a la memoria social, al generar emociones y valoraciones múltiples, corresponde a la de "buena vida en el campo", visualizada a partir de la contrastación directa con una vida en la ciudad mostrada como problemática y tortuosa.
En un contexto de dominancia de lo rural sobre lo urbano, según el cual "la marginalización, la discriminación, la desigualdad en los ingresos, las disparidades regionales y la división urbano-rural son manifestaciones elocuentes de brechas sociales" (PARRA-PEÑA, ORDONEZ y ACOSTA, 2013, p. 16), la palabra hecha canción, bien sea por los mismos habitantes rurales o por quienes son sensibles a sus situaciones de vida, se usa para expresar y dar sentido a una lucha específica: reivindicar la vida en el campo frente al sofisma de la vida en la ciudad.

Volviendo a lo expuesto en el primer párrafo, en un día de mercado, en algún municipio rural de Colombia, cuando los campesinos se toman un descanso luego de negociar sus productos en la plaza, reunidos en una tienda o cantina junto con sus familiares y amigos, se escuchan y tararean, entre las escuchadas en campo, canciones con títulos bastante sugestivos como: $\mathrm{Me}$ regreso al llano, Un ranchero en la ciudad, De regreso al campo y Del campo a la ciudad, Mañana regreso al campo, Regreso al campo, entre otros, que dan cuenta de la situación esbozada. Son relatos que también se oyen e interpretan en actos escolares conmemorativos, en fiestas y reuniones familiares y comunales, también programadas en emisoras locales, sintonizadas a diario por los pobladores del campo.

Desde una perspectiva analítica, se trata de textos musicalizados que expresan sistemas de creencias que, por el hecho de ser sociales y estar inevitablemente vinculados a las luchas, intereses y conflictos de un grupo, hacen contrapeso a la representación dominante (LONDOÑO-VÁSQUEZ y BERMÚDEZRESTREPO, 2013, p. 508): vivir en la ciudad como símbolo de bienestar, progreso y ganancia de estatus personal. Son canciones que, en representación de un grupo social particular (habitantes rurales campesinos que resisten al poder del discurso dominante), exponen y comparten miradas disidentes, con intensiones persuasivas.

Es justamente la existencia de este corpus de textos lo que dio origen a la siguiente inquietud intelectual: frente a la amenaza que supone la decisión migratoria, en la lucha por reivindicar la vida en el campo en un contexto social que incita a la partida, en canciones como las mencionadas, ¿qué sistemas de creencias están típicamente asociados a las intenciones persuasivas de los usuarios del lenguaje? 


\section{Metodología}

Una vez definida la pregunta orientadora, el primer paso fue conformar el corpus textual de análisis. Se eligieron las canciones De regreso al campo y Me regreso pal llano, ambas escogidas por su representatividad y pertinencia en relación con la temática de estudio, escuchadas por el autor durante giras de campo.

La primera, a ritmo de carranga, género jocoso y fiestero oriundo de la región andina colombiana, que pregona el sentir, la cotidianeidad, los anhelos y raciocinios de la gente del campo (CÁRDENAS y MONTES, 2009, p. 272), compuesta por Nicodemus Viviescas e interpretada por el maestro Tocayo Vargas. La segunda, a ritmo de rap, género urbano que en su versión contestaría cuestiona el orden social y cultural (CASTIBLANCO, 2005, p. 255), compuesta e interpretada por Pablo Cardoza y Reinaldo Rivas, integrantes del grupo venezolano Campesinos Rap.

El paso siguiente fue definir la vía analítica, optando por recurrir a fundamentos generales del análisis sociocrítico, dada su utilidad para interrogar y atribuir significado a los textos seleccionados. Los principios asumidos como guía de lectura fueron:

- "Que toda creación artística es también práctica social y, por ello, producción ideológica" (DUCHET, 1991, p. 43).

- Que todos los textos y discursos están constituidos en relación con otros, por lo que cada texto es un interdiscurso; que en el texto se entrecruzan y dialogan diversas posiciones ideológicas que dan cuenta de tensiones sociales; que fijar la atención sobre los puntos conflictivos permite reconstruir el sentido del texto e identificar las ideologías subyacentes (CROS, 1986, p. 79).

- Que lo expuesto en el discurso no es de ninguna forma lo real, sino las diversas maneras en que lo real es conocido de forma distinta e inclusive antagónica; que, como aporte al conocimiento de la realidad social, al investigador le corresponde reconstruir lo que se dice, lo que se conjetura y antagoniza sobre dicho mundo socialmente construido, aclarando los conflictos de una determinada época (ROBIN y ANGETON, 1991, p. 51-54).

Teniendo en cuenta estas premisas y asumiendo como guía la pregunta de investigación, a partir de una lectura a profundidad, al adaptar lo expuesto por Attride (2001, p. 390-394), se procedió a identificar e inferir conjuntamente en los textos: a) tensiones, contradicciones y conflictos asociados a "vida en el campo" y "vida en la ciudad", b) posiciones ideológica en diálogo, y c) cuestionamientos específicos al discurso dominante, al considerar, para todos los casos, su expresión en mensajes tanto explícitos como latentes.

Concretamente, el análisis del corpus textual, recurriendo a principios de la teoría fundamentada (STRAUSS y CORBIN, 1990), se realizó así: a) lectura repetitiva de los textos, b) identificación de temáticas comunes (puntos de conflicto) y agrupamiento de fragmentos textuales por afinidad temática, c) propuesta de unidades de análisis exponentes de tensiones y contradicciones específicas, y d) análisis contextual de los discursos en diálogo contenidos en cada unidad analítica.

La lectura a profundidad de ambos textos permitió identificar cinco puntos principales de conflicto, que dieron origen a igual número de unidades analíticas, desarrolladas una a una en la presentación de resultados. Estas son: a) condiciones de seguridad, en un contexto que opone la paz vivida en el campo al peligro y la violencia experimentada en la ciudad, b) condiciones de inclusión social, en un escenario urbano que, contrastado con el rural, no ofrece a sus habitantes condiciones y oportunidades de vida equitativas para satisfacer sus más elementales necesidades y derechos, c) valoración vocacional, en un ambiente urbano en el que el saber campesino es menospreciado e invisibilizado como medio de adaptación al entorno citadino, d) privatización de bienes y recursos comunes, en una ciudad en donde, a diferencia de lo que ocurre en el campo, el espacio y los recursos públicos y de uso colectivo son cada vez más escasos, y e) relaciones interpersonales, en una urbe en donde el egoísmo de sus pobladores se sobrepone a la solidaridad anhelada, vista como todavía prevaleciente en el medio rural de vida.

Fragmentos de las canciones fueron agrupados por unidad analítica, para ser posteriormente comparados. El cotejo permitió identificar discursos comunes, contrastantes o relacionados, tomados como base para el análisis de contenido.

Aunque se procedió de esta manera, es decir, identificando y separando unidades de significación y sentido con fines analíticos e interpretativos, en cada momento se buscó mantener la unidad argumentativa 
de los textos entrecruzándolos. Así se conservó lo comunicado como un todo en las canciones sobre los contrastes entre ambas formas de vida.

\section{Presentación del corpus textual}

Debido a que las letras de las canciones elegidas no están trascritas ni en los volantes que acompañan a los discos ni en las páginas web de los grupos, fue necesario hacer una transcripción propia para trabajar con ellas y reproducirlas aquí. Esto hace que, sobre todo para la canción Me regreso pal Llano, existan algunas imprecisiones respecto a nombres y vocablos regionales. Se sugiere a los lectores seguir la letra de las canciones escuchando los audios disponibles en: https://www.youtube.com/watch?v=Cx5nNJOHZik y https://www.youtube.com/watch?v=VF46e8pN7Is

\section{De regreso al campo}

(Autor: Nicodemus Viviescas) (1a) Hasta el campo fue mi tía, esa vieja aparecida, qué donde yo hubiera sabido, nunca le hubiera creído, toda la paja que me habló.

(2a) De qué en la ciudad había un montón de garantías, pa' que su ilustre sobrino terminara ese destino de tirar el azadón.

(3a) Al llegar quedé aterrado, de ver que me habían robado, las chichiguas que tenía y unas vainas que traía de presente pa' llegar.

(4a) Mis primos avergonzados, de verme acampesinado, con malicia se reían y a la cucha le decían que no me dejara entrar.

(5a) No más que por ser tan culto, empecé a llevar del bulto, en ese mismito instante, en qué di un paso adelante en esa grande ciudad.

(6a) Me fui disque a encontrar empleo, Pero ni para hacer aseo, ni para lavar los platos, ni para embolar zapatos, me quisieron ocupar. (7a) De pronto un ingeniero, diciendo que, por ser bueno, y nada más por ayudarme, y sin decir si iba a pagarme, va y me pone a trabajar.

(8a) Pasan como tres quincenas, y como me daba pena, porque le tenía respeto, y decían que al arquitecto no le podían reclamar.

(9a) Un día me le fui acercando, y ahí mismito preguntando, que uno por ser de vereda, es que a las cuantas quincenas le comienzan a pagar.

(10a) No más me dijo, atrevido, cómo es que se le ha ocurrido, que yo tenga que pagarle, nada más por enseñarle cómo debe trabajar.

(11a) Me fui más desconsolado que un perro recién capado a suplicarle a mi tía que los platos de comida no me los fuera a cobrar.

(12a) Me dijo: no le rebajo, porque es que este es mi trabajo, y es que no le da vergüenza o acaso no le da pena jartarse las tres quincenas y no venirme a pagar. (13a) Por si fuera poca cosa, tuve que pedir limosna, para comprar el tiquete y agarrar yo mi maleta y a Bolívar fui a parar.

(14a) Pa' mi tía quedé de rata, porque dijo que la plata, en trago la había gastado, y que no le había pagado por irme a vagabundear.

(15a) Ahora estoy en mi vereda, donde a mí siempre me espera la gente que me ha querido, hermanos y amigos míos, pa' salir a pachanguear.

(16a) Después de largas faenas, cada quien con su morena, hablamos de amor sincero, $\mathrm{y}$ sin pensar en los cuernos que utilizan por allá.

(17a) Uno que se crio en el campo, no debe creerle al falso, que se jarta tres cervezas y descansa la cabeza, poniéndose a farolear.

(18a) Que diga barbaridades y que cuente vanidades, disculpe que no le crea, pero a yo de mi vereda no me vuelven a sacar. 


\section{Me regreso pal Llano \\ (Autores: Pablo Cardoza y Reinaldo Rivas)} viendo cosas diferentes, tantas chicas relucientes, perfumaban el ambiente. Con una vaina en los dientes, que parecían un rastrillo, le dije: ¿qué vaina es esa?, me dijo: esos son frenillos.

(5b) Y a ti, compadre, cómo te fue en la recorrida, seguro mucho bregaste por allá todos los días.

(6b) Explícame que te pasó en aquella travesía, tú que eres más criollito que un sancocho al medio día.

(7b) Esa vaina sí es verdad, Compadre, ahorita le cuento, las vainas que le pasa a uno, por nacer en el llano adentro. (8b) Me dispuse a caminar, y me afilé pa'la ciudad, como escuché muchos rumores, que allá la vida es calidad, recogí mis cuatro trapos, sin pensar ni reparar, y me encaminé ni más ni menos que del llano a la ciudad.

(9b) Cuando llego, compañero, eso era una fumacera, Ay, compadre, si usted viera, mujeres por donde quiera.

(10b) Me puse el saco terciado, como un veguero regiao, y caminando con cuidado, un poco medio asustado, de repente, compañero, se prendió una plomacera, yo sin saber qué es lo que era, ahí pegué fue la carrera.

(11b) Crucé como treinta calles, embalado como una fiera, mire compadre, le comento, que aquí la vaina no es muy buena.

(16b) Cargaba lentes oscuros, también un par de sarcillos, y no me quitó la plata porque la cargaba en el fundillo.

(17b) Ya no hallo ni qué hacer, viviendo por aquí en el centro, ¿será que tendré que irme de nuevo pal llano adentro?

(18b) Sí, compadre, vámonos, esta vaina sí es arrecha, todavía tengo recuerdos de tan malas experiencias.

(19b) Desde que ando por aquí, no hallo pa' dónde coger, el hambre me tiene estrechado y no tengo ni pal el café.

(20b) Pues no hay una vaina más sería que un veguero en la ciudad, uno limpio, feo y perdido, pa' qué se pone a inventar.

(21b) - Entonces qué vamos a hacer, compadre.

- Vámonos, compadre.

- Vamos, para dónde, compadre.

- Vámonos para el Llano. otra vez ni se le ocurra, caminar por esas calles donde no hay monte ni burra.

(13b) Yo también pasé trabajo, comprando unos interiores, hasta vomité tres veces, en unos tales ascensores.

(14b) Yo salí de todos los colores, la tensión se puso baja, de repente voy un tipo, pelo por una navaja.

(15b) Me dijo: quiero el billete. Le dije: primo no tengo nada, pero vino el desgraciado, y me empezó fue a revisar. (22b) ¿Qué voy a hacer?, si esta vaina no me gusta, yo soy un veguero regio y amargo como la brusca.

(23b) ¿Qué voy a hacer? $\mathrm{Pa}^{\prime}$ mi llano es que me voy, me regreso primo hermano, a cuidar de mis marranos.

(24b) ¿Qué voy a hacer? No sé qué hacer, ya parezco mismo borsa, estoy llevando mucha vaina, yo mejor me voy pa' Elorza. 
(25b) ¿Qué voy a hacer?

Ah, pues, no voy a saber,

recoja sus macundales,

que nos fuimos de una vez.

(26b) Mire primo, yo no vuelvo

a pisar tierras ajenas,

por estar con los inventos,

me he dejado una carrera.

(27b) Yo no vuelvo pa' esa vaina, ahí la broma no es muy buena, yo me tiendo pa' mi Llano, con mis vacas y mis ovejas.

(28b) Yo también cojo camino, pa' mi tierra, compañero, eso es muy malo un campesino viviendo en el extranjero. (29b) Me hace falta un chiquero, repleto de puro capón,

y una brisa sabanera revuelta con cagajón.

(30b) Usted mismito ya lo dijo, tiene toda la razón, yo no cambio oro por cobre, ni joropo por reguetón.

(31b) No se diga más del tema, se acabó la discusión, vámonos a comer pira, revuelta con chicharrón.

(32b) iQué voy a hacer! ¿Qué voy a hacer? Ya qué estoy en mi casita, pal centro yo volveré, pero será de pasadita. (33b) iQué voy a hacer! ¿Qué voy a hacer? Más nunca vuelvo por ahí, yo que quedo en mi fundito, sembrando y comiendo maiz.

(34b) iQué voy a hacer! ¿Qué voy a hacer? Ya que estoy en la sabana, mañana me voy pal el río, a ver si saco una cachama.

(35b) iQué voy a hacer! ¿Qué voy a hacer? Ah, pues, me voy con usted, ya que no hay necesidad de volver para allá otra vez.

\section{Resultados y discusión}

En ambos textos, la estrategia seguida para expresar la versión propia sobre "vida en el campo" y "vida en la ciudad" se basa en la valoración comparativa entre una y otra. Estimación sustentada en el relato de vivencias que, haciendo explícita la superioridad de la primera, a manera de distinción positiva, resalta los atributos negativos de la vida en la ciudad:

(18b) Sí, compadre, vámonos, esta vaina sí es arrecha, todavía tengo recuerdos de tan malas experiencias.

Son vivencias narradas que, en la voz decampesinos protagonistas de cada historia, hacen relucir lo positivo de habitar en el campo y lo pernicioso de hacerlo en la ciudad, táctica de contrastación que a su vez implica encubrir lo bueno de la contraparte y las cualidades negativas de lo propio. En este contexto, como parte de la valoración comparativa, la vida en el campo no es apreciada en sí misma, sino que de inmediato recurre a su supuesto contrario, la vida en la ciudad, y devela una particularidad a subvertir: la existencia de una dicotomía que no sólo señala opuestos sino también jerarquías conformes con la representación hegemónica (la vida en la ciudad jerárquicamente superior a la vida en el campo), ideología que es puesta en duda en el discurso estudiado.

Recurriendo a la comparación social, teniendo en cuenta que las valoraciones de los modos de vida no se hacen en el vacío sino en un contexto de comparación con otros (RIZO, 2006, p. 4), sustentado en las vivencias de personajes ficticios y como forma de quitar peso a la representación dominante, a la ciudad y a sus originarios les son adjudicadas propiedades contrastantes con una imagen de civilidad idealizada, que figurativamente debería semejarse a la ciudad contemporánea. En esta vía, lo narrado en las canciones tiene por intención atenuar la imagen de ciudad como eje de dinamismo, progreso y modernidad, al hacer una valoración inversa que la devela sumida en la inseguridad, el individualismo y la devastación ambiental, condiciones opuestas a las de un también idealizado ámbito rural, visto como depositario de paz, espíritu comunitario y equilibrio socioambiental (SZULC, 2004, p. 168).

Bajo esta lectura, próximo a lo expuesto por Tassara (2007, p. 11), la vida en la ciudad, expresión hegemónicamente coligada a los términos urbanidad y civilidad, así como a valores e ideologías que dan 
cuenta de "lo que es bueno, lo mejor, lo más educado y civilizado", es cuestionada. Misma vacilación que, al retirar de lo urbano parte de esa "civilidad" aludida, relativiza el sentido también hegemónicamente adjudicado a lo rural: "el campo como un lugar atrasado, rudo y no civilizado", cuya superación sería necesaria para la institución de una sociedad moderna y orientada por la lógica urbano-industrial capitalista de mercado (BONOMO et al., 2011, p. 687).

En coherencia con la táctica anteriormente descrita, a partir de la escenificación de gente de campo experimentando la ciudad, los textos narran un proceso de comparación intergrupal, en un contexto de desequilibrio a favor de lo rural campesino:

(30b) Usted mismito ya lo dijo,

tiene toda la razón,

yo no cambio oro por cobre,

ni joropo por reguetón.

Cercano a lo hallado por Bonomo et al. (2011, p. 682), al comparar su espacio y forma de vida con el de la gente de ciudad, para afirmarse como grupo, selectivamente la gente del campo hace relucir lo positivo de sus historias y vivencias cotidianas, omitiendo al mismo tiempo lo que podría ponerlos en desventaja o presentarlos negativamente frente a los de la ciudad. Es un proceder que, al centrar la atención en las diferencias, convenientemente desestima las semejanzas o circunstancias sociales compartidas, en donde, los individuos que pertenecen al otro grupo serían concebidos como masa no diferenciada, en un proceso de uniformización del exogrupo citadino (2011, p. 185).

Haciendo parte del mismo juego, otra táctica persuasiva empleadas es, además de estereotipar a la gente de ciudad, incluir en el contra-discurso los estereotipos con que los citadinos caracterizan a la gente de campo (vale recordar expresiones todavía hoy empleadas en Colombia como "eso es duro pal campesino", "que no se le note lo montañero", "no sea agropecuario") usando sus significados a favor:

(4a) Mis primos avergonzados, de verme acampesinado, con malicia se reían y a la cucha le decían que no me dejara entrar.
En este caso, sabiendo que en la práctica comunicativa el oyente reconoce la connotación, aunque jocosa, despectiva de éstas y otras expresiones, incluirlas en el discurso serviría para contar y relevar a quien escucha cómo se es representado por los otros. Es un mecanismo que, a partir de la incorporación de otras voces (hecho que refleja la polifonía del discurso), dirige la atención hacia el reconocimiento de una contraparte prejuiciosa que discrimina y subordina a los del campo. Intencionalmente, comunicar que en el contexto urbano se puede ser agredido de esa forma buscaría generar sentimientos de rechazo y defensa contra la gente de ciudad, además de disentimiento en relación con la forma como los otros desinformada y preconcebidamente los representan.

Desde otra perspectiva, se trata de estereotipos que, en otras circunstancias, "alimentarían la timidez, el aislamiento y la dificultad de inserción en los espacios de dominio público, creando o reforzando la frontera entre los dos modos de vida (BONOMO y DE SOUZA, 2013, p. 410)", mas en esta ocasión, dándoles la vuelta, usados por los campesinos para fortalecer y restarle valor a una representación histórico-hegemónica que, con base en un preconcepto, pregona su inferioridad y los califica como atrasados e ignorantes.

Afín a esta maniobra, próximo a lo expuesto por Van DijK (1995, p. 157) sobre lo común de introducir hipérboles en el discurso ideológico para acentuar y reforzar lo negativo de los otros, en el caso de estudio, los actos ofensivos de los urbanitas y lo malo de la vida en la ciudad son ampliamente destacados mediante la exageración y descripción detallada de escenas que, además de producir miedo, advierten sobre algo que se quiere que sea visto como cotidiano en la urbe:

(10b) Me puse el saco terciado, como un veguero regiao, y caminando con cuidado, un poco medio asustado, de repente, compañero, se prendió una plomacera, yo sin saber qué es lo que era, ahí pegué fue la carrera.

(11b) Crucé como treinta calles, embalado como una fiera, mire compadre, le comento, que aquí la cosa no es muy buena. 
(12b) De vaina no lo mataron,

otra vez ni se le ocurra,

caminar por esas calles

donde no hay monte ni burra.

En consonancia con lo expuesto, describir situaciones que develan una ciudad violenta y peligrosa es un recurso usado en ambos textos como estrategia de diferenciación y realce de lo negativo de la vida en la urbe. Este tema será ampliado a continuación, al que se suman, derivados del análisis de resultados, otros referentes (unidades de análisis) igualmente útiles para cumplir dicho propósito.

\subsection{Un campo pacífico y una ciudad peligrosa}

Narraciones como la arriba citada, coincidentes y repetitivas en los textos, intentan proyectar en los espectadores una idea de gran ciudad en su totalidad atemorizante e insegura, es decir, una ciudad para nada deseable, contrastante con un campo representado como apacible en el que se correrían menos riesgos. Sumado a lo visto en los medios masivos de comunicación, a lo imaginado y lo oído de otros, mensajes como éste entrarían a hacer parte del acervo informativo a partir del cual los habitantes del campo (en especial quienes nunca han estado en la ciudad) decidirían sobre quedarse o partir, en un contexto en que la violencia urbana sería un desincentivo a la marcha:

(3a) Al llegar quedé aterrado, de ver que me habían robado, las chichiguas que tenía y unas vainas que traía de presente pa' llegar.

(14b) De repente voy un tipo, pelo por una navaja.

(15b) Me dijo: quiero el billete. Le dije: primo no tengo nada, pero vino el desgraciado, y me empezó fue a revisar.

(16b) Cargaba lentes oscuros, también un par se sarcillos, y no me quitó la plata porque la cargaba en el fundillo. (17b) Ya no hallo ni qué hacer, viviendo por aquí en el centro, iserá que tendré que irme de nuevo pal llano adentro?

En estos casos, como parte de la estrategia discursiva, la idea de un campo apacible y seguro, por lo menos cuando se hace referencia al territorio colombiano, enmascararía la existencia de un campo convertido en escenario de confrontación armada. Como es sabido, en términos generales y sin desconocer que la intensidad del conflicto varía geográficamente, la violencia asociada al conflicto político, económico y social nacional ha forzado a un sin número de pobladores rurales a migrar a ciudades capitales e intermedias bajo amenazas de vida (OCAMPO, MARTÍNEZ y ZULUAGA, 2015, p. 161), circunstancia a lo mejor oportunamente callada en ambos textos. Así, aun sabiendo que en el campo enaltecido en las canciones la situación de violencia podría ser igual o mayor que la presente en la ciudad, en éstas se muestra un campo en paz, que proyecta una añoranza, un anhelo de cambio, y comunica un llamado público a reconstituir el campo como un espacio favorable a la vida.

A pesar del talante dramático de los temas (inseguridad, violencia, discriminación social, maltrato), es preciso observar cómo en el discurso estudiado lo trágico es transformado en cómico. Recurriendo a la ironía, la imagen de ciudad poderosa, la hegemónicamente sobrepuesta al campo, es pausadamente desnudada, quedando al descubierto algunos de sus principales puntos críticos. Chistosamente, la gente de campo personificada en el discurso, en representación de esos campesinos casi siempre objetos de burla y estereotipados en los medios de comunicación, es ahora la que se mofa de algunos rasgos del comportamiento urbano hoy.

Como argumenta Pérez (2002, p. 188), "la ironía es el arma discursiva más importante para combatir el poder". En este caso, acogiendo la mirada de la misma autora, se trata de un humor social, irónico, que busca evidenciar los defectos, las contradicciones, las debilidades del poder hegemónico que la ciudad representa. Así, aunque la canción burlesca y sus temáticas reproduzcan también la ideología dominante, mostrando sus imperfecciones, debilitándola, la presenta como susceptible de duda. 


\subsection{Un campo para todos y una ciudad excluyente}

Siguiendo el argumento anterior, son varias las debilidades y contradicciones mostradas que, recorriendo a la ironía, ponen en cuestión la idea de superioridad de la ciudad:

(1a) Hasta el campo fue mi tía, esa vieja aparecida, qué donde yo hubiera sabido, nunca le hubiera creído, toda la paja que me habló.

(2a) De qué en la ciudad había, un montón de garantías, pa' que su ilustre sobrino terminara ese destino de tirar el azadón

(8b) Me dispuse a caminar, y me afilé para la ciudad, como escuché muchos rumores, que allá la vida es calidad, recogí mis cuatro trapos, sin pensar ni reparar, y me encaminé ni más ni menos que del llano a la ciudad.

En estos casos, el dominio de la gran ciudad, asumido como consecuencia de la concentración en ella de toda una serie de actividades, bienes y servicios puestos a disposición de sus habitantes, cuyo disfrute sería garantía de bienestar y desarrollo individual y colectivo, resulta ser lo primero a cuestionar. Al verificar esa idea-promesa, de acuerdo con lo narrado en las canciones, la gente de campo en la ciudad devela que lo dicho es una realidad a medias. Aunque es posible evidenciar dicha concentración, en la vivencia se constata que el acceso es fraccionado o limitado a algunos. El supuesto "montón de garantías" informado, opuesto a lo posiblemente hallado en un espacio de carencias, figura con que es representado el ámbito rural de vida desde la perspectiva hegemónica, se desvanece para los emigrados del campo.

Aquello oído de otros respecto a que "allá la vida es calidad" resulta no ser tan cierto. La ciudad conocida, anticipada a partir de la imagen mediatizada (la ciudad para todos, la ciudad de las puertas abiertas, la ciudad de oportunidades), a la que se asocian estilos de vida creados desde la publicidad y el consumo consonantes con determinado mito urbano, al ser puesta a prueba en la experiencia existencial, es apenas parcialmente comprobada (MARTÍN-BARBERO, 2002, p. 45; RIZO, 2005, p. 157). Esa ciudad preconocida, trazada en la mente de quien optó por partir, que sobrepone lo bueno a lo malo (sin desconocer que lo negativo o menos positivo también es expuesto por otros o los medios según la intención del momento) puede terminar en una gran decepción.

La ciudad percibida como un espacio capaz de cubrir los múltiples requerimientos de todos sus habitantes, al ser experimentada deja al descubierto un desfase entre dichas necesidades y lo que puede ofrecer (BOTERO, 1997, p. 120). El colapso de algunos servicios públicos, la falta de recursos de las administraciones municipales, el crecimiento físico y demográfico desmedido, la formación de grandes aglomeraciones humanas, la extensión de la ciudad marginada y la segregación poblacional se suman a la lista de problemáticas fundantes del desencuentro aludido (QUESADA, 2006).

En términos generales, ver que en la ciudad la supervivencia no está asegurada, que el acceso a alimentación, vivienda, empleo, seguridad y recreación es limitado, desencanta la imagen de ciudad preconcebida. Esto persuade a los interlocutores campesinos para que permanezcan en su lugar de origen, sin desconocer que a aquella ocasionalmente hay que ir para acceder a bienes y servicios aún allí concentrados, no disponibles en el campo:

(35b) iQué voy a hacer!

¿Qué voy a hacer?

Ah, pues, me voy con usted,

ya que no hay necesidad

de volver por allá [a la ciudad] otra vez.

(36b) iQué voy a hacer!

¿Qué voy a hacer?

Ya qué estoy en mi casita, pal centro yo volveré,

pero será de pasadita.

Así, aunque para el caso colombiano, la pobreza y la pobreza extrema en las zonas rurales $(46,1 \%$ y $22,1 \%$, respectivamente) superan considerablemente 
los niveles reportados para el medio urbano (30,3\% y 7\%) (PARRA-PEÑA, ORDONEZ y ACOSTA, 2013, p. 16), se pregona que emigrar no es la solución. Que la condición de vida alcanzada en el campo, como se verá a continuación, por múltiples razones puede ser superior a la lograda en la ciudad.

\subsection{De expertos en el campo a ignorantes en la ciudad}

En relación con el empleo, temática enfatizada en uno de los textos estudiados, se narra que para la gente del campo en la ciudad, conseguirlo y así generar los ingresos requeridos para su manutención, es un problema de gran dificultad a superar. Cuando llegan a la urbe y se disponen a hacerlo, de ser expertos agricultores o productores pecuarios, oficio que se aprende en el seno familiar como parte del proceso de socialización in situ, en la ciudad les es adjudicado el carácter de analfabetas funcionales (MÉNDEZ, 2005, p. 10). Es decir, en la lucha que implicaría terminar con el "destino de tirar en azadón", su saber resultaría poco útil para realizar oficios reconocidos como urbanos:

(6a) Me fui disque a encontrar empleo, pero ni para hacer aseo, ni para lavar los platos, ni para embolar zapatos, me quisieron ocupar.

En este caso, retomando lo relacionado con la persistencia de estereotipos y prejuicios, a la supuesta disfuncionalidad aludida se suma la discriminación por ser del campo y, más específicamente, por ser agricultor.

En primera instancia, la narración comunica que lo que en la ciudad queda para ellos corresponde a los oficios que exigen mínima especialización, los que en apariencia podría hacer cualquiera, los peor remunerados, los de menor reconocimiento social $y$, en general, ubicados en el mercado de trabajo informal (MÉNDEZ, 2009, p. 140); hecho que advierte a los emigrantes potenciales acerca de este riesgo de vulnerabilidad socioeconómica. También insinúa que, para algunos campesinos, en términos de cambio y mejoría, lo disponible en la ciudad no se diferenciaría mucho de lo disponible en el campo: trabajos asociados a la "agricultura de subsistencia", es decir, de escasa productividad, generadora de empleos mal pagos, inestables y con bajo potencial de crecimiento
(REARDON, BERDEGUÉ y ESCOBAR, 2004, p. 16); circunstancia que (sin ser la única) habla sobre lo poco significativo que, por lo menos en términos económicos, sería salir del campo a la ciudad.

En segunda instancia, la canción advierte que, por ser del campo, en la ciudad los campesinos comúnmente cargan el estigma de ignorantes, personas consideradas atrasadas, incultas e incapaces de asimilar costumbres y tecnologías modernas, hecho que, al descalificarlos ocupacionalmente, por prejuicio desconoce su acervo de capacidades. En este caso, lo que se desconoce corresponde a los saberes y destrezas asociados al oficio de agricultor, sobre todo a aquellas capacidades por su generalidad aplicable a otros oficios, incluidos algunos reconocidos como urbanos. En su labor cotidiana, un agricultor es un tomador constante de decisiones (qué, cuánto, dónde sembrar), un administrador de negocios que maneja presupuestos y cuentas, un promotor y comercializador de productos y un analista de mercados, experiencia que facilitaría su adaptación a otros ámbitos productivos.

En tercera instancia, lo dicho también llama la atención sobre la explotación laboral a la que los campesinos suelen ser sometidos, en un ámbito en el que ser del campo estereotípicamente los ubica en un peldaño de ignorancia, inferioridad y sumisión:

(7a) De pronto un ingeniero, diciendo que, por ser bueno, y nada más por ayudarme, y sin decir si iba a pagarme, va y me pone a trabajar.

(8a) Pasan como tres quincenas, y como me daba pena, porque le tenía respeto, y decían que al arquitecto no le podían reclamar.

(9a) Un día me le fui acercando, y ahí mismito preguntando, que uno por ser de vereda, es que a las cuantas quincenas le comienzan a pagar.

(10a) No más me dijo, atrevido, cómo es que se le ha ocurrido, que yo tenga que pagarle, nada más por enseñarle cómo debe trabajar. 
Según este contexto, lo expuesto en la canción resalta cómo en la urbe el riesgo de ser explotado y de sucumbir por necesidad a ello es predecible, siendo la ciudad un escenario hostil en el que la pobreza de la gente, incluyendo a los migrantes campesinos, es aprovechada por otros para generar riqueza, incluso recurriendo a mecanismos institucionalmente avalados, como el mercado flexible de trabajo que hoy acentúan la explotación y la desigualdad social (HOLGUÍN y INSUASTY, 2014, p. 90).

Comunicar lo anterior sería una exhortación a querer y valorar el trabajo del campo, a evitar el sometimiento que, en las circunstancias descritas, significaría a los campesinos vincularse en desventaja al mercado urbano de trabajo, mensaje que también convida a contemplar la posibilidad de retornar y recobrar la vida de agricultor:

(23b) ¿Qué voy a hacer?

Pa' mi llano es que me voy, me regreso primo hermano, a cuidar de mis marranos.

Retomando a Bonomo y De Souza (2013, p. 412), el trabajo en el campo, en este caso referido a la cría de animales y al cultivo de especies vegetales (actividades en la que los campesinos son expertos), asumiría una connotación opuesta al realizado en la ciudad. Mientras en el campo estaría idealmente asociado a la expresión y puesta en práctica de virtudes y valores asociados a la autosostenibilidad, el cuidado, la provisión familiar y la formación de personas "de bien", en la ciudad estaría ligado a la preservación de un modelo de acumulación del capital, atado a la explotación de los otros y a la perpetuación de la desigualdad social.

Como se presentará en el siguiente apartado, el modelo descrito no sólo cosifica y convierte en mercancía a la gente y su fuerza de trabajo, sino también a cada una de sus necesidades básicas y al propio espacio físico-social en que se vive, con consecuencias sobre la supervivencia de la gente del campo en la ciudad.

\subsection{De un espacio rural común a uno urbano mercantilizado y privado}

En un contexto como el narrado, en el que para subsistir en la urbe se depende de un empleo casi siempre informal y mal pagado, donde la lógica capitalista de mercado se sobrepone a cualquier otra forma de economía o intercambio, los campesinos viviendo en la ciudad extrañan la faceta no mercantilizada del campo:

(11a) Me fui más desconsolado que un perro recién capado a suplicarle a mi tía que los platos de comida no me los fuera a cobrar.

(12a) Me dijo, no le rebajo porque este es mi trabajo...

Interpretativamente se cuenta que, en la urbe, contexto social en el que no existe ninguna necesidad humana que no sea explotada por el comercio (WIRTH, 2005, p. 14), todo tiene precio y se convierte en mercancía, la supervivencia de la gente de campo se hace más complicada. Alimentos, alojamiento, agua, vivienda, entre los bienes más básicos, tienen que pagarse para poder ser consumidos, creando una relación de mayor dependencia humana de los mercados de bienes y de trabajo.

Es una situación que en los textos se contrasta con lo que aún ofrece el campo en términos de producción para el autoconsumo, existencia de recursos de uso común y pervivencia de las relaciones sociales solidarias, que, haciendo contrapeso a la idea anclada de dureza de la vida y el trabajo en el campo, muestra una faceta más amable de éste. En este sentido, lo contado en las canciones deja entrever que, en tiempos de crisis, cuando abunda el desempleo y los recursos individuales y familiares se hacen escasos, la ciudad mínimamente brinda opciones de subsistencia (WIRTH, 2005, p. 13), por lo menos distintas a la mendicidad o a las llamadas actividades de rebusque (venta ambulante al menudeo, reciclaje, cuidado de vehículos en la calle, entre otros):

(13a) Por si fuera poca cosa, tuve que pedir limosna, para comprar el tiquete y agarrar yo mi maleta y a Bolívar fui a parar.

Existe, entonces, la ciudad que no ofrece alternativas, en donde es difícil conseguir empleo y la racionalidad capitalista de mercado rige las relaciones 
sociales. Ésta es contrastada con un campo que, sin dejar de hacer parte de la sociedad global, mantiene algunas diferencias al respecto enfatizadas en el discurso cantado:

(33b) ¿Qué voy a hacer?

Más nunca vuelvo por ahí, yo que quedo en mi fundito, sembrando y comiendo maiz.

(34b) ¿Qué voy a hacer?

Ya que estoy en la sabana, mañana me voy para el río, a ver si saco una cachama.

En el campo, producir para el autoconsumo parte de los alimentos requeridos por el hogar, sin que esto signifique no vender excedentes o producir para el mercado, es una práctica mantenida hasta hoy, que coadyuva a ganar grados de seguridad alimentaria. En tiempos de crisis, cuando en el campo también escasea el trabajo, por ejemplo, tener en la finca algo para comer (frutas y verduras producidas en el traspatio, especies menores criadas para el consumo familiar) es una posibilidad a favor, no siempre a disposición de los habitantes urbanos, a pesar del actual avance de la agricultura urbana. Es aquí cuando cobra sentido quedarse "sembrando y comiendo maíz", cavilación surgida cuando el campesino en la ciudad se ve con hambre y sin tener "ni pal café".

Parecido a lo anterior, cuando uno de los personajes canta la intención de ir al río "a ver si saco una cachama", se habla de la existencia aún en el campo de recursos de uso común, actualmente casi inexistentes en la ciudad, donde el proceso de privatización de la propiedad y el despojo de los bienes comunes exhiben un estado avanzado. Simplificando la situación, en el campo, cuando se requiere proteína animal para alimentar a la familia, además de poder comprarla en el expendio, se puede optar por ir al río a pescar cuando no se tiene dinero o se desea, posibilidad cada vez más negada en la ciudad, bien sea porque está prohibido, el bien fue dado en concesión o, incorporando el componente ambiental ("cuando llego compañero, eso era una fumacera"), las fuentes están contaminadas.

Rescatando lo oculto en las canciones, subrayar la existencia en el presente de esos bienes convida a pensar en su preservación. Como advertencia a los habitantes del campo, lo contado incita a mirar críticamente los efectos negativos del proceder urbano-industrial desarrollista, hoy más evidente en las ciudades, pero también cada vez más reconocibles en el campo, con el progreso de la agroindustria a gran escala, la agricultura extractiva e intensiva, el cambio del uso del suelo y la apropiación comercial del patrimonio natural. En este contexto, la crítica realizada contribuiría a reforzar lo que sería una ideología de la conservación, que llamaría a la gente del campo a resistir y actuar contra el avance de la depredación, mercantilización y privatización de los recursos del entorno básicos para la pervivencia (ÁVILA y LUNA, 2013, p. 64), todavía a disposición de todos.

Como se verá a continuación, sería un llamado no únicamente a conservar la naturaleza y los recursos naturales. Se trata también de mantener las formas de relación social que lo permiten, aún menos centradas en obtener lucro inmediato, ponerle precio a todo y generar de ello ganancia.

\subsection{De un campo solidario a una ciudad egoísta}

Mientras se expresa que en el campo la gente es más solidaria, fraterna y desinteresada, se muestra que entre las personas de ciudad son otros los valores dominantes. El utilitarismo, el individualismo, la explotación mutua y el espíritu de competencia figuran entre los esbozados, contrastando con otros más afines a la acción comunitaria y solidaria. Como ejemplo, la escena más arriba descrita muestra cómo la tía, un miembro de la familia que sucumbió a la urbanización, que asimiló una serie de pautas, sistemas de valores, comportamientos y actitudes considerados urbanos (STAROSTA, 1994, p. 66), a diferencia de lo que se esperaría en el campo, cobra al sobrino por quedarse y alimentarse en su casa: fui "a suplicarme a mi tía que los platos de comida no me los fuera a cobrar".

En estas circunstancias, lo que se recrimina a la vida en la ciudad es el agotamiento de las relaciones solidarias, trocadas por otras de orden utilitario, promotoras de egoísmo e individualidad. Así, mientras en el campo sigue siendo común la donación y el intercambio de servicios, alimentos, cuidados y fuerza de trabajo entre familiares y amigos (TORRES, 2002, p. 82), en la ciudad, espacio en que cada vez más se resquebrajan las relaciones de parentesco y vecindad, estas formas de interacción social desaparecen, 
menoscabando la confianza y la solidaridad entre la gente y posicionando la vida calculadora y egoísta. Se trata de un sistema de intercambios y reciprocidades próximo a lo expuesto desde la antropología (MALINOWSKI, 1986; MAUSS, 1971; GODELIER, 1998), que se agota cada vez más en la urbe, que obliga a la gente del campo en la ciudad a ajustar sus prácticas a un contexto carente de vida en comunidad, donde las relaciones entre la gente son más utilitarias que solidarias, donde, a pesar de la proximidad física, el distanciamiento social es muy notable.

Es justamente ese distanciamiento el que se pregona como no deseable. En las canciones se advierte que quien migra para la ciudad, una vez allá, estará solo, que difícilmente contará con una red de apoyo como la conocida en el campo, circunstancia que incitaría a no partir.

En contralectura, afín a la estrategia de ocultamiento selectivo, lo narrado niega la inexistencia en la ciudad de nichos de mayor proximidad entre la gente, como podría ser el caso de la vida en el barrio: entidad vecinal en la que comunicabilidad, la solidaridad, la tolerancia y la sociabilidad entre quienes lo habitan destaca (BURAGLIA, 1999, p. 26; RIZO, 2006, p. 10). Un espacio socialmente próximo a la vereda: conglomerado humano o vecindad rural donde la conciencia de grupo y la unidad de propósitos distingue a sus habitantes (FALS BORDA, 1995, p. 45), dando lugar a una red de solidaridades e intercambios mutuos (TORRES, 2002, p. 83):

(15a) Ahora estoy en mi vereda, donde a mí siempre me espera la gente que me ha querido, hermanos y amigos míos, pa' salir a pachanguear.

En términos generales, la ciudad caracterizada en las canciones, está debilitada en su superioridad a partir de la mirada del otro. Es el habitante del campo el que intencionalmente la describe enfatizando sus defectos, incita a los oyentes a no abandonarlo, así como también a retornar:

(27b) Yo no vuelvo pa' esa vaina, ahí la broma no es muy buena, yo me tiendo pa' mi Llano, con mis vacas y mis ovejas. (28b) Yo también cojo camino, pa' mi tierra, compañero, eso es muy malo un campesino viviendo en el extranjero.

(29b) Me hace falta un chiquero, repleto de puro capón, y una brisa sabanera revuelta con cagajón.

Relatar lo que sería la típica experiencia de un campesino en la urbe contribuiría a reforzar la imagen de ciudad como un lugar equivocado, como un espacio que no es el propio, en un contexto en que vivir allí casi equivaldría a hacerlo "en el extranjero", sometiéndose a un doloroso proceso de adaptación. Convocando a todos los sentidos, los textos cuentan que dolería también dejar de percibir los olores del campo: "una brisa sabanera revuelta con cagajón", saborear la comida hecha a mano y en casa: "una torta de casabe" recién tostada o dejar de ver a diario el monte, la sabana o las montañas. Se trata de situaciones cotidianas que, a pesar de su aparente simplicidad, en términos de satisfacción y bienestar significan mucho para los habitantes del campo, extrañadas sobre todo cuando se está en la ciudad y hoy ansiadas por los propios citadinos, en búsqueda de "algo" que allí se ha ido agotando (conexión con la naturaleza, la tierra y la comunidad) como resultado del proceso de civilización urbana (DE PAULA, 2005, p. 245; BUNCE, 2003, p. 18; MÉNDEZ, 2012, p. 203).

Bajo este enfoque, en un ámbito social donde lo urbano es hegemónico y lo rural sigue siendo explicado en función de sus rezagos y carencias respecto a la imagen de ciudad moderna, mostrar otras facetas de la vida en el campo, aquellas que para sus habitantes de base representan bienestar y riqueza, es una forma de ejercer contrapoder. En este contexto, lo dicho en las canciones tendría como fin compartir otra mirada sobre la vida en el campo, incorporar lo expuesto por los propios campesinos acerca de su lugar y modo de vida (MATIJASEVIC y RUIZ, 2013, p. 36), facilitar a los otros comprender que la percepción de calidad de vida es multidimensional y que la riqueza de un grupo o individuo va mucho más allá de su ubicación espacial, actividad económica, cantidad de ingresos y capacidad de consumo. 
(17a) Uno que se crio en el campo, no debe creerle al falso,

que se jarta tres cervezas

y descansa la cabeza,

poniéndose a farolear.

(18b) Que diga barbaridades

y que cuente vanidades,

disculpe que no le crea,

pero a yo de mi vereda

no me vuelven a sacar.

Como intención general, el contenido del discurso convoca a ser más precavidos frente a la imagen de ciudad que aún cautiva la atención y el deseo de la gente del campo. Llama a tomar precauciones frente a aquella visualización de la urbe positivamente maquillada, la que todo ofrece, la que a cualquiera posibilita cumplir el sueño urbano, en ambos textos desenmascarada. No obstante, es preciso ver que esa ciudad idealizada, la descrita por sus habitantes cuando hablan a los otros sobre ella, más que una ciudad falseada, es una imaginada que efectivamente existe en la mente de los narradores, aquella que quisieran que fuera, en la que quisieran vivir, un prototipo o modelo de lo que debería ser (BOTERO, 2005, p. 126), hoy anhelada por su misma gente.

Vale terminar diciendo que, en el contexto de estudio, la anterior observación también tendría sentido, es decir, que parte de la representación de vida en el campo expuesta y defendida en las canciones correspondería a la imagen de un campo idealizado. Resaltando lo positivo y haciendo a un lado las sombras como recurso elegido para marcar oposición, intencionalmente se recrea un campo, un modo de vida y un contexto rural no sólo basado en la realidad actual sino también en nostalgias, expectativas y deseos: un campo en paz, librado de la guerra, habitado por gente solidaria, ambientalmente sostenible, con oportunidades de empleo, inmerso en una sociedad mayor que valore tanto material como simbólicamente la agricultura como actividad sustentadora de la vida humana y, consecuentemente, la profesión de agricultor.

\section{Conclusiones}

Interpretativamente, el estudio permite concluir que las categorías vida en el campo y vida en la ciudad mantienen contemporáneamente su vigencia no como descriptores de dos modos disímiles de vida, con características fijas y virtudes opuestas sustantivas. Lo hacen como expresiones vivenciales que conjunta y complementariamente permiten evidenciar el avance diferenciado y el posicionamiento progresivo de los valores asociados a la lógica capitalista urbanoindustrial de desarrollo (individualismo, utilitarismo, legitimización de la inequidad, mercantilización y explotación de la vida y la naturaleza) como orientadores universales de las relaciones sociales e interpersonales en la sociedad como un todo, incluyendo la resistencia a dicha propensión.

Al mantener distinciones aparentemente dicotómicas, ambas representaciones dan cuenta de lo que podría reconocerse como los efectos nocivos de la difusión y sobreposición hegemónica de esta lógica sobre cualquier tipo de relación humana, proceso surgido en la ciudad, pero expandido por el espacio totalizado (LIMONAD y MONTE-MOR, 2012, p. 9). Hoy, en un contexto en el que se promulga que lo urbano ya no se identifica sólo con lo perteneciente a la ciudad (BRENNER, 2013, p. 50), la defensa del campo y la vida en el campo hecha por quienes viven allí y se reconocen a sí mismos como campesinos se enfoca en avivar y fortalecer los valores, actitudes y costumbres a su juicio erosionados por la expansión (desigual) de la urbanización y la vida urbanizada sobre la sociedad en general. En este sentido, reivindicar el derecho al campo y la vida en el campo comporta reclamar el derecho a una forma de vida en aparente extinción, a recrear un mundo más vivible, incluyendo, también, un tipo más afable de ciudad y vida en la ciudad.

Es sobre esta base que el campo adquiere el rol de espacio de resistencia, papel evidenciado en los textos a partir de la expresión de argumentos a favor de recuperar parte de lo perdido: las relaciones solidarias, el conocimiento mutuo y la proximidad social entre la gente, el derecho al uso común de los recursos, la valoración no sólo comercial de las cosas, entre lo destacado.

En esta línea, "regresar al campo" o "regresar al llano", aludiendo al título de las canciones estudiadas, significa resistirse a un modelo de mundo hoy casi naturalizado y en continua expansión que, metafóricamente, expresa su fealdad en varios aspectos: la manera egoísta en que la gente interactúa, la discriminación social, la cosificación de la vida, la 
mercantilización y explotación de la naturaleza, la contaminación ambiental y la transformación de la gente en cosa útil (o inútil). "Regresar al campo", es decir, tomar distancia de la ciudad, espacio representado como portador y eje de expansión del modo de vida urbano, simbolizaría avanzar en remediar lo que ya ha sido permeado por esa criticada forma de ser, pensar y actuar, de la cual el mismo campo no está exento.

Asociado a lo último, revelar la vulnerabilidad del campo a la irrupción de la lógica y la cultura urbana, principalmente en sus facetas reprochadas o criticadas, comunica el reconocimiento de este espacio no como un ente aislado sino en relación con el global, pero aún con capacidad de selección. Ante tesis que prescriben que el raciocinio urbano-industrial capitalista ha penetrado tan intensamente en los espacios rurales, hasta el punto en que hoy es complicado percibir diferencias en actitudes, hábitos, valores, estructuras y relaciones de producción entre habitantes del campo y la ciudad (BAIGORRI, 1995), la anti-ideología formula que la cultura propia, sin dejar de ser receptiva o abierta al influjo urbano global, selecciona lo que aporta a su perfeccionamiento, incorporándolo, adaptándolo o resignificándolo, dejando fluir lo que en su momento no interesa.

Vale mencionar, a propósito, el ejemplo que nos da Campesinos Rap, grupo que, en representación de la gente de campo o del interior, usando sus propias palabras, interpreta "un hip hop bien criollito", rural, provinciano o campesino. Si bien en el contexto local se incorporan elementos estéticos inscritos al hip hop globalizado y, en especial, al rap como expresión musical de la contra-cultura urbana, en el campo éstos son reconfigurados y creativamente acogidos para dar cuenta de lo propio. Para el caso particular, manteniendo su esencia contestataria, el rap se incorpora como medio de expresión y resistencia campesina, como instrumento útil para hacer públicas las versionas propias sobre la vida en el campo y modo de generar conciencia, acción y reflexión en referencia a los problemas y potencialidades rurales.

En relación con la decisión migratoria, se concluye que, en la lucha por reivindicar la vida en el campo, debilitar los sistemas de creencias dominantes, mostrar sus inconsistencias y descubrir sus lados oscuros es una forma de crear contra-discurso frente a la idea de ciudad idealizada, maniobra cimentada en contar lo que usualmente se omite. Hacer públicas experiencias privadas, frecuentemente calladas por la gente por vergüenza a demostrar debilidad, fracaso o inadaptabilidad a la vida moderna en la ciudad, sirve en este caso para que quienes piensen migrar atenúen sus expectativas sobre la vida en la urbe. Recurrir a la canción popular, darles la palabra a personajes ficticios, habladores que no tienen nada que temer y además convierten los recuerdos angustiosos en relatos cómicos y alegres, es la base de la estrategia utilizada para desvelar una ciudad moderna agreste.

En este contexto, pensando en términos de política pública, emular en lo rural la "vida moderna", aquella puesta en juicio en los textos no sería el camino para desincentivar la partida y actuar sobre las brechas entre el campo y la ciudad, pues, ¿qué ganarían los pobladores de un campo en el que se reproduce y expande la criticada lógica urbano-industrial capitalista? Además de garantizar a sus pobladores el acceso universal tanto a bienes de interés social (educación, salud, nutrición, agua, vivienda, saneamiento y protección social) como a oportunidades de inclusión productiva (empleo, fuentes propias de generación de ingresos) (RAMÍREZ et al., 2016, p. 10), salvaguardar la forma de ser rural, la manera de vivir junto a otros en el espacio rural y de vivir de lo que el propio medio proporciona, en los términos analizados, sería un componente necesario para generar, allí, condiciones duraderas de avance haca el bienestar social.

Para finalizar, vale tener en cuenta que, ejercicios como el realizado, además de explorar las representaciones actuales acerca del campo y la ciudad, buscan exponer su contenido político. Visualizar los textos musicalizados como micro-prácticas de poder y contrapoder, tomando en consideración las experiencias y opiniones de los grupos subalternos, hace parte de la propuesta desarrollada. Así, en un contexto en que lo urbano trata de imponerse y explayarse sobre la sociedad como un todo, resistencias como las estudiadas, a pesar de parecer inofensivas al poder dominante, suman fuerza a anti-ideologías capaces de oponerse al orden hegemónico.

¿Qué expresan sobre el mundo y la sociedad actual aquellos que, teniendo voz propia, son raramente escuchados?, ¿qué otras alternativas usan para narrar sus perspectivas cuando en los medios comerciales de comunicación impera el desestímulo a la diversidad cultural?, ¿cómo hacen uso de otras expresiones artísticas para enunciar su discurso disidente? Entre las principales, son preguntas que 
invitan a seguir indagando sobre la expresión popular y la comunicación alternativa.

\section{Referencias}

ATTRIDE, J. Thematic networks: an analytic tool for qualitative research. Qualitative Research, v. 1, n. 3, p. 385-405, 2001.

ÁVILA, P. y LUNA, E. Del ecologismo de los ricos al ecologismo de los pobres. Revista Mexicana de Sociología, México, v. 75, n. 1, p. 63-89, 2013.

BAIGORRI, A. De lo rural a lo urbano. In: CONGRESO ESPAÑOL DE SOCIOLOGÍA, 5., 1995, Granada. Memorias..., Granada: Federación Española de Sociología, 1995. Disponible en: < http://sistemamid. com/panel/uploads/biblioteca/7097/7128/7129/83387. pdf $>$. Consultado en: 9 sep. 2016.

BONOMO, M. et al. Das categorias aos grupos sociais: representações sociais dos grupos urbano e rural. Psicologia, Ciência e Profissão, Brasília, v. 31, n. 4, p. 676689, 2011.

. y DE SOUZA, L. Representações hegemónicas e polémicas no contexto identitário rural. Avances em Psicologia Latinoamericana, Bogotá, v. 31, n. 2, p. 402-418, 2013.

BOTERO, L. Ciudades imaginadas, identidad y poder. Espiral, Guadalajara, v. 7, n. 8, p. 113-145, 1997.

BRENNER, N. Tesis sobre la urbanización planetaria. Nueva Sociedad, Buenos Aires, n. 242, p. 38-66, 2013.

BUNCE, M. Reproducing rural idylls. In: CLOKE. P. (Ed.). Country visions. Harlow: Pearson Education, 2003, p. 14-30.

BURAGLIA, P. El barrio desde una perspectiva socioespacial. Hacia una redefinición del concepto. Bogotá: Barrio Taller, 1991. Disponible en: <http://www.barriotaller. org>. Consultado en: 12 oct. 2016.

CÁRDENAS, F. y MONTES, M. Narrativas del paisaje andino colombiano: visión ecológica de la música carranguera de Jorge Velosa. Revista de Antropología Iberoamericana, Madrid, v. 4, n. 2, p. 269-293, 2009.

CASTIBLANCO, G. Rap y prácticas de resistencia: una forma de ser joven. Reflexiones preliminares a partir de la interacción con algunas agrupaciones bogotanas. Tabula Rasa, Bogotá, n. 3, p. 253-270, 2005.

CROS, E. Literatura, ideología y sociedad. Madrid: Gredos, 1986.

DE PAULA, S. Natureza, ruralidade e experiência urbana. In: MOREIRA, R. (Org.). Identidades sociais.
Ruralidades no Brasil contemporâneo. Rio de Janeiro: DP\&A, 2005, p. 237-253.

DUCHET, C. Posiciones y perspectivas sociocríticas. In: MALCUUZYNSKI, M. (Coord.). Socicríticas prácticas textuales: cultura de fronteras. Amsterdam: Rodopi, 1991, p. 43-50.

FALS BORDA, O. Campesinos de los Andes. Bogotá: Iqueima, 1995.

FRITH, S. Hacia una estética de la música popular. In: CRUCES, F. (Ed.). Las culturas musicales: lecturas de etnomusicología. Madrid: Trotta, 2001, p. 413-436.

GODELIER, M. El enigma del don. Madrid: Paidós, 1998.

HOLGUÍN, E. y INSUASTY, A. Capital, sujeto y ciudad. Lecturas de la ciudad y la crisis humanista: el caso Medellín. Revista El Ágora USB, Medellín, v. 14, n. 1, p. 87-96, 2014.

HORMIGOS, J. y MARÍN, A. La construcción de la identidad juvenil a través de la música. Revista Española de Sociología, Madrid, n. 4, p. 259-270, 2004.

LIMONAD, E. y MONTE-MÓR, R. Por el derecho a la ciudad, entre lo rural y lo urbano. Scripta Nova: Revista Electrónica de Geografía y Ciencias Sociales, Barcelona, v. 16, n. 418, p. 1-25, 2012.

LONDOÑO-VÁSQUEZ, D. y BERMÚDEZRESTREPO, H. Tres enfoques sobre los estudios críticos del discurso en el examen de la dominación. Palabra Clave, Bogotá, v. 16, n. 2, p. 491-519, 2013.

MAGNO, L., DOULA, S. y PINTO, N. Todo o mundo conhece a gente agora": cultura e identidade de jovens rurais em Minas Gerais (Brasil). Revista Latinoamericana de Ciencias Sociales, Niñez y Juventud, Manizales, v. 9, n. 1, p. 305-319, 2011.

MALINOWAKI, B. Los argonautas del pacífico occidental. Barcelona: Planeta-Agostini, 1986.

MARTÍN-BARBERO, J. Desencuentros de la socialidad y reencantamiento de la identidad". Análisis: cuadernos de comunicación y cultura, Barcelona, n. 29, p. 45-62, 2002.

MATIJASEVIC, M. y RUIZ, A. La construcción social de lo rural. Revista Latinoamericana de Metodología de la Investigación, Buenos Aires, v. 5, n. 3, p. 24-4, 2013.

MAUSS, M. Sociología y antropología. Madrid: Technos, 1971.

MÉNDEZ, M. Contradicción, complementariedad e hibridación en las relaciones entre lo rural y lo urbano. Revista MAD, Santiago, n. 13, p. 1-25, 2005.

MÉNDEZ, M. Incursión ocupacional rural en entornos no agrícolas y urbanos: tendencias y desafíos. In: DE GRAMMONT, H. y MARTINEZ, L. (Comps.). 
La pluriactividad en el campo latinoamericano. Quito: FLACSO-Ecuador, 2009, p. 127-144.

. Movilidad rural-urbano-rural como fenómeno configurante de dinámicas socioespaciales alternativas. Perspectiva Geográfica, Tunja, v. 17, p. 193-212, 2012.

OCAMPO, M., MARTÍNEZ, M. y ZULUAGA, S. Campesinos desplazados forzados en Colombia caminan de la mano del eterno retorno a la violencia: vulneración y potencia de vida". Psicologia USP, São Paulo, v. 26, n. 2, p. 161-168, 2015.

OSLENDER, U. Discursos ocultos de resistencia: tradición oral y cultura política en comunidades negras de la costa pacífica colombiana. Revista Colombiana de Antropología, Bogotá, n. 39, p. 203-235, 2003.

Tradición oral y memoria colectiva en el Pacífico colombiano: hacia la construcción de una política cultural negra. Guaraguao. Revista de Cultura Latinoamericana, Barcelona, v. 9, n. 20, p. 74-104, 2005.

PARRA-PEÑA, R., ORDÓÑEZ, L. y ACOSTA, C. Pobreza, brechas y ruralidad en Colombia. Coyuntura Económica, Bogotá, v. 43, n. 1, p. 15-36, 2013.

PÉREZ, M. La sociocrítica del sociohumor: la ironía en la risa popular. Filología y Lingüística, San José, v. 28, n. 2, p. 185-200, 2002.

PNUD. Colombia rural: razones para la esperanza. Bogotá: PNUD, 2011.

QUESADA, F. Imaginarios urbanos, espacio público y ciudad en América Latina". Pensar Iberoamérica: revista de cultura, Madrid, n. 8, 2006. Disponible en: < http:// www.oei.es/pensariberoamerica/ric08a03.htm $>$. Consultado en: 23 sep. 2016.

RAMÍREZ, J. et al. Bienes y servicios públicos sociales en la zona rural de Colombia. Brechas y politicas públicas. Bogotá: CEPAL, 2016.

REARDON, T., BERDEGUÉ, J. y ESCOBAR, G. Empleo e ingresos rurales no agrícolas en América Latina: síntesis de aplicaciones de política. In: CEPAL (Ed.). Empleo e ingresos rurales no agrícolas en América Latina: síntesis de aplicaciones de politica, Seminarios y Conferencias No. 35. Santiago de Chile: Naciones Unidas, 2004, p. 15-33.

RIZO, M. Comunicación e interacción social. Aportes de la comunicación al estudio de la ciudad, la identidad y la inmigración. Global Media Journal, Monterrey, v. 1, n. 2, p. 151-169, 2005
. Conceptos para pensar lo urbano: el abordaje de la ciudad desde la identidad, el habitus y las representaciones sociales. Bifurcaciones, Talca, n. 6, p. 1-13, 2006.

ROBIN, R. y ANGENOT, M. La inscripción del discurso social en el texto literario. In: MALCUUZYNSKI, M. (Ed.). Sociocríticas prácticas textuales: cultura de fronteras. Amsterdam: Rodopi, 1991, p. 51-80.

SÁNCHEZ, R. Apuntes sobre música, canciones y sociedad: el caso de una isla caribeña 1970-1991. Intersticios. Revista sociológica de pensamiento crítico, Madrid, v. 8, n. 1, p. 193-207, 2014.

STAROSTA, P. Ruralization and rurality. Three perspectives. In: SIMES, D. y JANSEN, A. (Edits.). Agricultural restructuring and rural change in Europe. Netherlands: Agricultural Wageningen, 1994, p. 65-75.

STRAUSS, A. y CORBIN, J. Basics of qualitative research. Thousand Lage Daks: Lage Publications, 1990.

SZULC, A. Mapuche se es también en la waria (ciudad). Disputas en torno a lo rural, lo urbano y lo indígena en la Argentina. Política y Sociedad, Madrid, v. 41, n. 3, p. 167-180, 2004.

TORRES, L. Autoconsumo y reciprocidad entre los campesinos andinos: caso Fómeque. Cuadernos de Desarrollo Rural, Bogotá, n. 48, p. 81-98, 2002.

VAN DIJK, T. Ideological discourse analysis. New Courant, v. 4, n. 1, p. 135-161, 1995.

VICH, V. y ZAVALA, V. Oralidad y poder: herramientas metodológicas. Bogotá: Norma, 2004.

WIRTH, L. El urbanismo como modo de vida. Bifurcaciones, Talca, n. 2, p. 1-15, 2005. Disponible en: <http://www.bifurcaciones.cl/2005/03/louis-wirthurbanismo/>. Consultado en: 19 sep. 2016.

\section{Referencias discográficas}

CARDOZA, P. y RIVAS, R. Me regreso pal Llano [grabada por Campesinos Rap]. En Lo más criollo del mapa [CD]. Venezuela: La base secreta, 2014.

VIVIESCAS, N. De regreso al campo [grabada por $\mathrm{T}$. Vargas]. En El hombre es hombre aunque la mujer le pegue [CD]. Colombia, 2009.

Todo o conteúdo deste periódico, exceto onde estiver identificado, está licenciado sob uma Licença Creative Commons (cc by 4.0 ) 